\title{
Clinical Simulations in Academic Courses: Four Case Studies Across the Medical SLP Graduate Curriculum
}

\author{
Amanda Stead \\ Pacific University, amanda.stead@pacificu.edu \\ Rik Lemoncello \\ Pacific University, rik.lemoncello@pdx.edu \\ Caitlin Fitzgerald \\ Pacific University, caitlinf@pacificu.edu
}

See next page for additional authors

DOI: https://doi.org/10.30707/TLCSD4.3/ACVJ1784

Follow this and additional works at: https://ir.library.illinoisstate.edu/tlcsd

Part of the Other Rehabilitation and Therapy Commons

\section{Recommended Citation}

Stead, Amanda; Lemoncello, Rik; Fitzgerald, Caitlin; Fryer, Melissa; Frost, Marcia; and Palmer, Rachael (2020) "Clinical Simulations in Academic Courses: Four Case Studies Across the Medical SLP Graduate Curriculum," Teaching and Learning in Communication Sciences \& Disorders: Vol. 4: Iss. 3, Article 6. DOI: https://doi.org/10.30707/TLCSD4.3/ACVJ1784

Available at: https://ir.library.illinoisstate.edu/tlcsd/vol4/iss3/6

This Pilot Studies is brought to you for free and open access by ISU ReD: Research and eData. It has been accepted for inclusion in Teaching and Learning in Communication Sciences \& Disorders by an authorized editor of ISU ReD: Research and eData. For more information, please contact ISUReD@ilstu.edu. 


\title{
Clinical Simulations in Academic Courses: Four Case Studies Across the Medical SLP Graduate Curriculum
}

\begin{abstract}
Simulation practices are growing in both popularity and necessity within speech pathology programs. Simulation use can serve to not only minimize client risk but to increase student confidence and competence prior to patient contact, particularly with low incidence or medically fragile patients. This paper describes and reflects on four individual simulation experiences within one graduate speech language pathology program and their outcomes. The use of both simulated patients and mannequin training resulted in an increase in students' perception of knowledge and confidence in their clinical skills with medical patients.
\end{abstract}

\section{Keywords}

Simulation, Clinical Skills, Cognitive Rehabilitation, Dysphagia, Medical, Feeding, FEES, Mannequin

\section{Cover Page Footnote}

Work for the FEES training simulation was funded by the HEDCO Foundation to Dr. Lemoncello and Professor Frost.

\section{Authors}

Amanda Stead, Rik Lemoncello, Caitlin Fitzgerald, Melissa Fryer, Marcia Frost, and Rachael Palmer 


\section{Introduction}

Graduate programs in Communication Sciences and Disorders (CSD) are faced with increasing challenges in providing high-quality clinical education, such as developing externship sites with diverse populations, ensuring adequate preparation of clinical supervisors, assessing student clinical competencies, and providing opportunities for students to develop entry-level clinical skills across the expanding scope of practice (American Speech-Language-Hearing Association [ASHA], 2007). Each graduate program bears the responsibility of providing the opportunity for all graduates to obtain the necessary knowledge and skills for clinical practice across the major disorder categories (Council on Academic Accreditation in Audiology and Speech-Language Pathology [CAA], 2017). Within the area of medical speech-language pathology (SLP) clinical education, changes in healthcare reimbursement, productivity standards, supervision requirements, and lack of access to local healthcare facilities all contribute to the challenge of placing graduate students in medical SLP settings (e.g., hospitals, skilled nursing facilities, home health, etc.) for practicum experiences. Nonetheless, each graduate program must show evidence that graduates possess the requisite knowledge and skills to assess and treat disorders areas across the lifespan, while also demonstrating accountability, integrity, effective communication skills, clinical reasoning, evidence-based practice, concern for individuals served, cultural competence, professional duty, and collaborative practice (CAA, 2017). Because of these growing challenges, the Council for Clinical Certification (CFCC) updated the certification standards to allow inclusion of up to 75 supervised direct clinical contact hours to be acquired through clinical simulation methods (CFCC, 2016). Simulations can help increase standardization, equity, consistency and provide a safe learning environment for student clinical training (Quail et al., 2016).

Clinical simulations, in a variety of forms, offer a viable educational tool to allow CSD students to acquire professional competencies and skills (Macbean et al., 2013). Dudding and Nottingham (2018) outlined 5 primary modes of simulation used in healthcare training across disciplines:

- Standardized Patients - A person simulates an actual patient in a standardized repeatable way

- Task Trainers - A device that trains a particular skill

- Mannequins - A human-like simulator to mimic human functions

- Computer-Based Simulation - A computer-based technology often utilizing gaming technology and Augmented Reality

- Immersive Virtual Reality - A computer based three-dimensional spaces for immersive learning

Although clinical simulation has long been a standard educational practice in other health professions, such as medicine (Cook et al., 2011), the field of CSD has adopted the use more recently. A growing number of studies have described the effective use of simulation in the training of SLP and audiology students (Benadom \& Potter, 2010; Brown, 2017; Hill et al., 2010; MacBean et al., 2013; Quail et al., 2016; Ward et al., 2014). As one example, Brown (2017) suggested that simulation allows the student to learn technical skills separate from the patient, giving students the freedom to make mistakes, reflect, remediate, and demonstrate their skill competence without directly impacting a patient's care. For example, Brown advocated for task trainers to allow students time to independently practice a skill (e.g., cerumen management) and to self-identify when they are ready for supervisor assessment. Following such task-specific skill development, 
students may then be advanced to a standardized patient to provide an additional opportunity to practice and demonstrate their communication and counseling skills in a clinical simulation. Through this graduated educational model, students will be better prepared for clinical practice (Brown, 2017). As another example, Hill and colleagues (2010) reviewed the literature on standardized patients in clinical education and described the benefits and challenges associated with developing standardized patient clinical experiences. The authors described how such experiences could be applied to SLP education to foster communication, interaction, and specific clinical skills through authentic safe experiences with immediate real-time feedback.

When considering integrating simulation techniques into a clinical education program, it is also important to address pedagogy (Dudding et al., 2019). Quality simulation learning experiences (SLE) should shift the locus of learning responsibility to the learner by: allowing for active practice with immediate, specific, constructive feedback in a safe and realistic environment with repeated opportunities for practice and skill development; fostering critical thinking and metacognition through active engagement with expert clinician supervisors at a level of complexity suitable to the learner; and developing skills that are clearly identified through specific measurable learning objectives with clear outcomes for assessing competency. Dudding and colleagues advocate for a three-phase approach to SLE: pre-briefing, the simulation experience, and debriefing. Pre-briefing provides orientation to the SLE and clarity on objectives, expectations, roles, and assessment. Debriefing immediately after the SLE offers an opportunity for additional feedback, reflection, and re-connection back to the learning objectives and big-picture of clinical practice.

A recent national survey of SLE in CSD programs (Dudding \& Nottingham, 2018) revealed an emerging interest in SLE with standardized patients and computer-based simulations among the most frequently used simulation techniques., However, they noted a lack of integration of SLE into the curriculum and of agreement on learner evaluation. Despite the interest in SLE, lack of resources (e.g., time, equipment) and lack of knowledge were cited as barriers to SLE implementation (Dudding \& Nottingham, 2018). The authors called for more faculty training opportunities about SLE and increased resource investment in simulation technologies, with continued research focused on SLE implementation, effectiveness, and learner assessment (Dudding \& Nottingham, 2018).

At Pacific University, the master's program in SLP strives to integrate academic knowledge and clinical skills throughout the 5-semester curriculum. Academic and clinical faculty collaborate to scaffold learning across the curriculum through guided experiences in the classroom, clinical lab sessions, clinical seminars, and clinical practicum. Faculty who teach aspects of medical SLP have also collaborated to scaffold learning experiences across the program (e.g., medical continuum of care, medical terminology, reimbursement). The program requires 71 semester credit hours, including seven required courses related to medical SLP practice (Communication and Aging, Dysphagia, Aphasia, Motor Speech Disorders, Voice Disorders, Acquired Brain Injury, Progressive Neurological Disorders; See Table 1.), a clinical seminar focused on medical SLP topics, and two elective course options (Advanced Diagnostics, Medical SLP; See Table 1.). 
Table 1

Curriculum Schedule Supporting Medical SLP Practice at Pacific University

\begin{tabular}{lllll}
\hline Fall $1^{\text {st }}$ year & Spring $1^{\text {st }}$ year & Summer $1^{\text {st }}$ year & Fall $2^{\text {nd }}$ year & Spring 2 $2^{\text {nd }}$ year \\
\hline $\begin{array}{l}\text { Communication } \\
\text { and Aging }\end{array}$ & Dysphagia & Motor Speech & Acquired Brain & \\
& & Disorders & Injury \\
& Aphasia & Advanced & Progressive \\
& & Diagnostics* & Neurological & \\
& & Dedical SLP* & & \\
& & & \\
& & &
\end{tabular}

*Denotes elective course

Similar to other programs, it is difficult to provide uniform experiences to all 35 graduate students (per year) in the program to ensure entry-level clinical skill competency across all areas of practice. The authors of this paper have embraced SLE as a technique to provide opportunities for each learner to acquire, practice, and develop entry-level clinical competency across the medical SLP curriculum. This is especially true for learning to apply highly useful, evidence-based treatments (e.g., spaced retrieval) across a variety of client profiles, learning to conduct high-stakes, task specific procedures (e.g., fiberoptic endoscopic evaluation of swallowing (FEES)), or learning clinical skills that would be difficult to guarantee for each student through clinical practicum (e.g., pediatric feeding). The purpose of this paper is to describe four specific SLEs employed across the medical SLP curriculum at Pacific University to support student learning and clinical competency development. As each SLE is described, the authors will reflect on issues related to implementation, effectiveness, and learner assessment.

\section{Case Examples}

Each of the four case examples described below has received approval from the Institutional Review Board at Pacific University. The first two cases discuss use of task trainer SLEs with mannequins to develop procedural skills with first-year graduate students; the latter two cases discuss use of simulated patient SLEs to develop clinical critical thinking with second-year graduate students. As each case is presented, the participating faculty in that specific SLE will share reflections on: the rationale for each SLE, preparation for the SLE, specific equipment used in the SLE, student learning objectives, the pre-briefing, simulation and debriefing procedures, results of learning outcome assessment, and a reflection on the experience.

\section{First-Year Graduate Student Skill Development Examples}

First-year graduate students at Pacific University are learning content related to medical SLP while gaining clinical experiences in school-based educational settings. In order to facilitate and foster development of specific clinical skills related to coursework in dysphagia, multiple hands-on lab experiences are provided as learning opportunities (Lemoncello et al., 2015). The first two case examples of SLE describe how task trainers with mannequins facilitated development of clinical procedural skills while students were first acquiring medical SLP clinical competencies. 
Case 1: FEES Mannequin Task Training. FEES is a medical procedure that requires clinical skill for advancing the endoscope through a patient's nasal cavity in order to view the pharynx and larynx during swallowing. Because of the nature of this procedure, students often report feeling nervous about engaging in FEES (Benadom \& Potter, 2010). Furthermore, this procedure is typically only encountered in medical centers, which means that not every student will have the opportunity to learn to pass an endoscope or obtain exposure to the procedure if they do not have a placement in a medical center. Benadom and Potter (2010) investigated simulation training for SLP graduate students to learn FEES. The authors demonstrated that repeated task training with a simulator, whether a life-like mannequin or a non-life-like simulator, improved both student skill with inserting the scope and confidence ratings (Benadom \& Potter, 2010). Because of the lower incidence but growing use (Bax et al., 2014) of FEES in clinical practice, faculty decided to offer a FEES task trainer simulation to first-year graduate students as part of the dysphagia course. All 35 first-year graduate students completed the dysphagia course in the second semester of their first year.

Preparation. Two faculty participated in this SLE. To prepare for this SLE, faculty had completed training in FEES (ASHA, 2002) to ensure adequate procedural fluency. First-year graduate students had been exposed to FEES as part of their dysphagia course, including didactic learning, live demonstration of the procedure on a classmate in-class, and had completed a FEES video analysis competency assessment requiring $100 \%$ achievement to diagnose physiological impairments on ten single-swallow video clips (administered through the online Learning Management System).

Equipment. Training allowed students to learn how to pass a portable endoscopic system with a flexible adult transnasal endoscope (ATMOS FEES Portable System, with an ATMOST distal chip flexible endoscope and integrated LED light source) on a life-like mannequin with realistic looking silicone nasal, oral, pharyngeal, and esophageal anatomy (PHACON Throat Assistant Art-No S00010) These tools were acquired by Pacific University through grant funding in 2018.

Learning Objectives. The purpose of this SLE was to allow students to gain technical skill in passing the endoscope from the nares to the pharynx on the mannequin task trainer, while identifying anatomy and assessing for physiology. Specific learning objectives included: (a) demonstrate proficiency in handling the endoscope to move in three dimensions, (b) explain the procedure to the "patient" (mannequin) without technical jargon, (c) advance the endoscope through the nasal cavity and pharynx to arrive at home position within 60 seconds, (d) identify typical adult anatomy of the nasal cavity, nasopharynx, oropharynx, larynx, and hypopharynx, and (e) instruct the "patient" (mannequin) to perform tasks that assess the physiology of the velopharynx, base of tongue, pharyngeal walls, and larynx.

Pre-Briefing. Although all 35 first-year graduate students enrolled in the dysphagia course were invited to participate in an optional FEES lab outside of class time to gain experience with the equipment and procedure, an outcomes study was conducted with a smaller cohort of first-year graduate students $(n=18)$ enrolled in a Medical SLP elective course in the third semester of their graduate program. As part of the Medical SLP course, students had the opportunity to continue to practice passing the endoscope on the task-trainer mannequin as often as they would like 
throughout the semester. The endoscope and mannequin were set up each session at the back of the classroom so students would have easy access. Each day, a different item would be hidden in the mannequin's upper airway to either create a nasal obstruction or to demonstrate oropharyngeal residue. As students practiced endoscopic procedures, faculty asked them to anonymously document their abnormal findings (in clinical writing) on a small piece of paper. As part of the pre-briefing for this SLE, faculty instructed students on the purpose of this SLE (including the opportunity for low-stakes practice on the task trainer mannequin), the learning objectives, that faculty would provide direct training for initial passes, the nature of independent practice to shift the learning to the student, and that competency assessment would not count toward their course grade.

SLE Procedure. As each student practiced, they were instructed to use appropriate personal protective equipment (e.g., gloves and universal precautions), explain the procedure to the "patient" (mannequin), position the mannequin as well as their own hands and body for best body posture, efficiently pass the endoscope through the nasal cavity and into the pharynx, and to locate and label anatomical structures. Students were also instructed to ask the "patient" to complete a physiological exam as the instructor moved the mannequin tissues (e.g., uvula can be made to raise or lower, pharyngeal walls can be made to constrict, or larynx can be made to adduct). A faculty member directly supervised each student's initial passes until the student was able to demonstrate correct procedural and anatomical knowledge. Following initial passes, students were encouraged to continue to practice as often as they would like, with new "hidden" items added each day.

Debriefing. During initial passes that were directly supervised, faculty offered real-time feedback to assist students with learning the procedure. As students began to practice independently, students were encouraged to seek out the faculty supervisor for any questions as they learned to self-evaluate. At the end of each class session in the Medical SLP course, the faculty member reviewed written responses that documented the "hidden object" and offered whole-class feedback about clinical writing that described the item and location. Each day, students were asked as a whole group to share their experiences with the mannequin task training, any challenges, or any insights into their emerging skills.

Assessment. All 18 students enrolled in the Medical SLP elective course demonstrated competency that achieved the five learning objectives. An IRB-approved survey study was conducted at the end of the course to assess student perceptions on the experience. The survey asked about student confidence with the procedure (12 questions rated on a 4-point Likert-type scale), how many passes it took for students to feel comfortable with the procedure, and three open-ended questions about their learning, feelings, and the overall experience. Seven out of 18 (39\%) students in that elective course completed the survey (see Table 2). 
Table 2

Student Responses to Anonymous Survey About FEES Task Trainer Experience

\begin{tabular}{|c|c|}
\hline $\begin{array}{l}\text { Question Stem } \\
\text { I feel confident that I can... }\end{array}$ & $\begin{array}{l}\mathrm{M} \\
(\mathrm{SD})\end{array}$ \\
\hline effectively explain the FEES procedure prior to inserting the endoscope. & $\begin{array}{l}1.14 \\
(0.38)\end{array}$ \\
\hline identify the structures of the nasal passages. & $\begin{array}{l}1.43 \\
(0.53)\end{array}$ \\
\hline identify the structures and movements of the velopharyngeal port. & $\begin{array}{l}1.43 \\
(0.53)\end{array}$ \\
\hline identify the structures and movements of the pharynx. & $\begin{array}{l}1.29 \\
(0.49)\end{array}$ \\
\hline identify the structures and movements of the larynx. & $\begin{array}{l}1.29 \\
(0.29)\end{array}$ \\
\hline $\begin{array}{l}\text { insert and manipulate the endoscope transnasally in a timely manner (less } \\
\text { than } 60 \text { seconds). }\end{array}$ & $\begin{array}{l}1.14 \\
(0.38)\end{array}$ \\
\hline $\begin{array}{l}\text { insert and manipulate the endoscope in a manner that causes minimal } \\
\text { discomfort. }\end{array}$ & $\begin{array}{l}2.00 \\
(0.00)\end{array}$ \\
\hline effectively anchor the scope. & $\begin{array}{l}1.43 \\
(0.53)\end{array}$ \\
\hline $\begin{array}{l}\text { manipulate the endoscope within the nasal passages and pharynx to obtain the } \\
\text { desired view(s). }\end{array}$ & $\begin{array}{l}1.43 \\
(0.53)\end{array}$ \\
\hline use appropriate ergonomic posture and scope handling techniques. & $\begin{array}{l}1.71 \\
(0.49)\end{array}$ \\
\hline apply sound reasoning and problem-solving during the FEES procedure. & $\begin{array}{l}1.86 \\
(0.38)\end{array}$ \\
\hline complete the FEES procedure in a safe and competent manner. & $\begin{array}{l}1.71 \\
(0.49)\end{array}$ \\
\hline
\end{tabular}

Note. Confidence scale ranged from 1=Strongly Agree to 4=Strongly Disagree.

$n=7$ respondents

As a result of this SLE, students reported greatest confidence with explaining the procedure and developing fluency with the procedure; they reported lowest confidence with conducting the procedure in a manner that minimizes patient discomfort, likely because they had not yet 
completed the procedure on a human patient. The survey also asked students to report the number of passes they completed as well as how many passes it took before they felt comfortable inserting and manipulating the endoscope. Students reported they practiced multiple times (range: $4-15 ; M$ $=7$ ), and that they felt comfortable with the procedure after the second or third attempt (range: 2 $3 ; M=2$ ). In response to open-ended questions, students reported that this task trainer experience improved their knowledge of anatomy and the FEES procedure:

- "It was very helpful to practice both the passing of the scope as well as practicing terminology and discussion associated with this procedure. This exercise and practice was very life-like."

- "It was great being able to practice when there were simulated items to look for as well because it made me think critically about what I was looking at and what it might look like in an actual person."

- "The simulation was a nice way to ease into instrumentals without the pressure of juggling every other aspect of being a clinician."

- "By practicing and getting the nerves settled from the mechanics of using the endoscope, I could focus on putting the scope where I wanted to and using brain power to examine the structures. After a couple of passes, it felt more comfortable in terms of hand, arm, and anchor placement."

- "This experience allowed me to fully grasp the FEES procedure and the 'feeling' and maneuvers of the scope as you complete the instrumental exam. It also helped me think about what structures I am seeing and how a person's swallow may look for different diagnoses. I now feel way more comfortable explaining what this exam is and hope to continue my training to be able to use out in the field."

When asked specifically about how this task-training experience may have helped alleviate their fears about FEES, students reported:

- "Lots of fears prior to this exercise. The basic fear about how to do this has disappeared. Remaining is only the fear of what it will be like with a living breathing patient that is moving around. "

- "I was worried that I wouldn't be able to manipulate the scope efficiently and effectively. Now that I have had this experience, I feel much more comfortable manipulating the scope and understand how to change the angles."

- "I was afraid the scope would be more sensitive to my movements which would result in pain/discomfort of the 'patient.' The scope is very easy to manipulate and I would feel much more comfortable passing a scope with an actual patient based on this experience."

- "I was worried about inserting the scope and causing the patient a lot of pain as I would try and maneuver the scope in the pharyngeal area. Now, I feel a lot better about how to guide the scope through the nasal cavity and the slight wrist motions you can make to see different angles."

When asked about how to improve this learning experience, students reported:

- "This was a tremendous learning experience. It would be so great if we could all have the opportunity to pass these on each other after having done it with a mannequin."

- "This was extremely helpful and being able to practice it by ourselves really helped my learning experience." 
- "Maybe after the first couple pass attempts, being coached on the anatomy \& physiology to start, focusing attention on what we're looking for and where to go. Maybe incorporating the process into a case study so we have to end up ordering a FEES, then going in and finding *something*, then making a diagnosis, treatment plan and goals based on our findings."

- "It was great overall! I would like to see some additional live passes on individuals. It would also be nice to see how a video is recorded and processed."

Reflection. Students demonstrated procedural competency with FEES using a mannequin task trainer for low-stakes practice in order to gain initial competency with a medically complex procedure. This simulation allowed students the opportunity to gain experience without the clinical pressures of client discomfort, moving structures, or varied anatomy. Thus, it enabled students to learn to use the endoscope and navigate through "typical" anatomy while reducing their anxiety and fears. Primary feedback to improve this activity focused on the next developmental level to learn to pass the endoscope on human participants. Since 2018, faculty have continued to implement the mannequin task trainer in the dysphagia required course, medical SLP elective course, and have added a stroboscopy live demonstration to the Voice Disorders required course. In spring 2019, with procedures in place for informed consent, faculty began supervising students learning to pass the endoscope on each other after learning the procedure with the mannequin task trainer. As of fall 2019, 70 graduate and 29 undergraduate students have gained exposure to the endoscopic evaluation and use of this equipment for swallowing and voice disorders. Overall, the mannequin task-trainer SLE was found to be effective for: increasing knowledge of swallowing and voice anatomy and physiology; increasing task fluency and mastery for passing and manipulating the endoscope; and decreasing fears and anxieties about this medical procedure prior to human practice. This is consistent with the work by Benadom and Potter (2011) and a study by Ward and colleagues (2014) who studied tracheostomy skills in a part-task trainer. Participants in their SLE reported considerable increase in confidence and accomplishment of knowledge for management of tracheostomized patients. Future research will investigate the potential benefits of using the task-training mannequin by comparing how effectively and efficiently students pass the endoscope on a human volunteer either with or without having previously practiced with the mannequin simulation.

Case 2: Pediatric Feeding Task Training. Pediatric feeding is an area that requires specialized knowledge and skills, but graduate students often lack the opportunity to engage with this area in clinical practicum experiences. Because of this, an SLE was developed to offer a clinical application opportunity to graduate students in the practice of infant feeding, with an emphasis on cleft palate feeding and caregiver training. The primary faculty supervisor for this SLE had previously spent 7 years in clinical practice on a cleft palate team, pediatric feeding team, and in the Neonatal Intensive Care Unit as well as supervised numerous SLP graduate students in this setting. In the clinical setting, the faculty supervisor had observed that students were uncomfortable handling and providing hands-on assessment and treatment to the infant population. This experience was offered to provide a simulated opportunity to build confidence and skills.

Preparation. First-year graduate students had previously been exposed to infant feeding as part of their dysphagia course, including didactic learning, video examples for case discussion, and exposure to different bottles for feeding. Two faculty participated in this SLE. As part of the 
Medical SLP elective course, faculty guided students through an in-depth exploration of pediatric upper airway disorders, evaluation and treatment of cleft and craniofacial and resonance disorders, and included a culminating experience at a local medical center, where students attended lectures from members of the cleft and craniofacial team (including a plastic surgeon, genetic counselor, SLP, and audiologist). To prepare for this SLE, faculty collaborated to develop six specific learning stations, with step-by-step instructions to use specified feeding systems and strategies (discussed below), and to gather needed materials for each learning station.

Equipment. Realistic, racially diverse infant doll models (Breastfeeding Education Models from Cascade Healthcare Products - Models 62409 and 61407) were used. Additionally, the SLE utilized the Medela SpecialNeeds Feeder, Pigeon bottle/nipple system, Dr. Brown's Specialty Feeding System, and the Mead Johnson Cleft Lip/Palate Nurser. Swaddling blankets and Soothie 0-3mo pacifiers were also included.

Learning Objectives. The purpose of this SLE was to allow students to gain comfort and technical skill in infant feeding fundamentals as well as specialized feeding practices with infants with cleft palate. Specific learning objectives included: (a) demonstrate proficiency in swaddling an infant, (b) adequately position an infant for feeding in both upright and side-lying positions, (c) demonstrate procedures to elicit a non-nutritive suck, (4) demonstrate technique of external pacing while "feeding" the infant, (d) demonstrate functional use of each bottle system, and (e) explain the feeding system, positioning, and therapeutic techniques to the "caregiver" (another student).

Pre-Briefing. Although all 35 first-year graduate students completed the required dysphagia course, this SLE was offered as part of the Medical SLP elective course in the third semester of their graduate program ( $n=15$ students). The pediatric feeding SLE was a 4-hour experience that occurred during scheduled class time. At the beginning of the SLE, faculty-oriented students to the purpose of the SLE and the learning objectives. Faculty also reminded students that competency assessment would not count toward their course grade.

SLE Procedure. The SLE began with a 20-minute review of fundamental principles of infant feeding and highlighted considerations for medically fragile infants and infants with cleft palate. There was a focus on the mechanics of feeding and how feeding strategies and specialized feeding equipment could increase safety and efficiency during feeding. For the next 20 minutes, faculty demonstrated use of the four bottle systems and four feeding strategies (i.e., swaddling, side-lying or upright positioning, non-nutritive sucking, and external pacing). For the next three hours, students worked in pairs to rotate through six different stations, spending about 30 minutes at each station. One station was dedicated to each bottle system, and the final station focused on handling and positioning. At each station, students first spent 15 minutes learning the strategies and procedures until confident with the skill and equipment (see Figure 1). Students were then asked to use the second 15 minutes at each station to provide "caregiver" training to their partner on the rationale and specific use of that feeding system or strategy. Two faculty members were available to support learning, assess student competency development, and provide real-time feedback throughout the SLE. By the end of the SLE, students were also tasked with writing up a home program recommendation (e.g., how to prepare the infant for feeding, bottle type, and positioning and pacing recommendations) to send home with families at the final station they completed. Students shared these written recommendations with the "caregiver" partner and were asked to 
provide the rationale for these written recommendations then verbally review the home program with their partner.

\section{Figure 1}

\section{Student in the Simulated Pediatric Feeding Lab Practicing a Skill to Elicit a Non-Nutritive Suck}

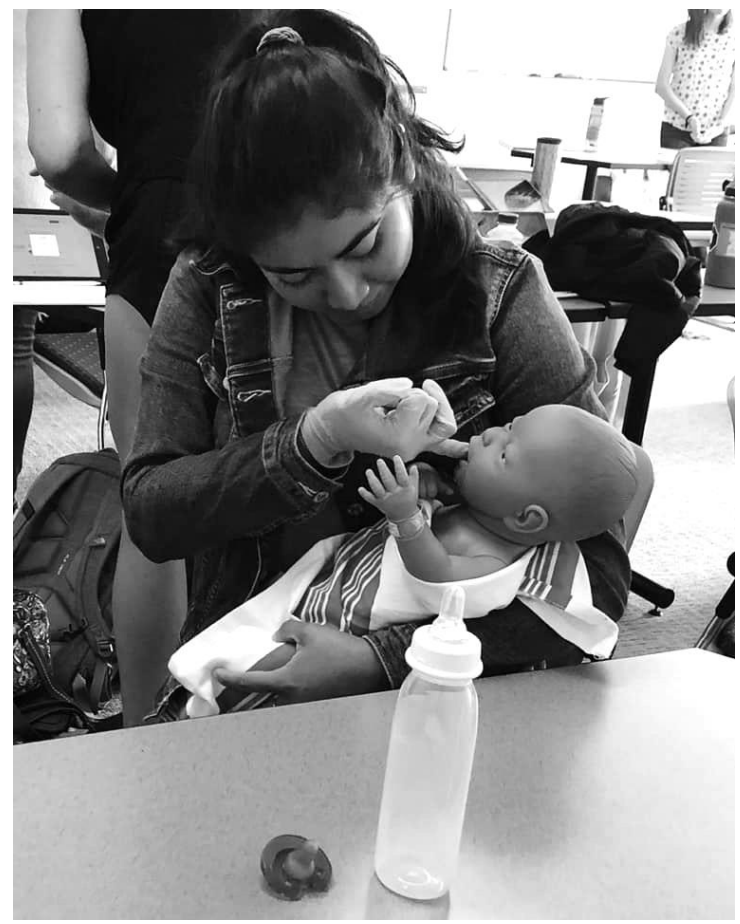

Debriefing. At the end of this SLE, students reconvened as a whole group for debriefing. Faculty prompted students to reflect on the experience, tying the experience back to the learning objectives. The group shared ideas to compare and contrast the different bottle systems, discussed challenges and experiences with infant handling techniques, reflected on how to share information with "caregivers," and considered application to future clinical practice across the range of feeding tools and strategies. The debriefing also included discussion about home program recommendations (verbal and written), the role of health literacy, and communication using simple, clear language.

Assessment. All students enrolled in the Medical SLP course met learning objectives based on supervisor impressions during the SLE. An IRB-approved survey study was conducted at the end of the experience to assess student perceptions. The survey asked three open-ended questions about their learning and about the overall experience. Three out of 15 students (20\%) in that elective course completed the survey (see Table 3 ). 


\section{Table 3}

\section{Sample of Survey Responses Following the Pediatric Feeding SLE}

\section{Question Responses}

What was the most "To actually have the products and 'baby' in front of us and be able to beneficial aspect of try each bottle and get some practice with wording and trying to explain this experience? to a 'parent.' Learning the information is so much different than trying to be able to say it out loud and explain it."

"I thought that was extremely helpful to see the different levels of flow and feeling the bottle nipples, especially the one for cleft. I thoroughly enjoyed the hands-on experience."

What did you learn "I learned about how different bottles can be appropriate for different through this clients. It depends on their needs, I learned that you do much more with simulation? a baby and parent then just feed them - I learned how to strategically explain a plan of care to a parent."

"Reduce the jargon and talk in layman's terms. My partners did a wonderful job being human beings, not other speech path students, so I was conscious of the terms I was using."
What suggestions
"I think it would be helpful to have 3 different infant case-examples and do you have for run through which bottles would be best, based on the infant's medical future feeding lab diagnosis and presentation!" simulation experiences?
"Creating separate stations each with its own scenario (with all the medical jargon and fake print-outs of what the monitor screen would look like) to apply our learning would be really fun and effective."

Reflection. Students demonstrated procedural competency with infant feeding tools and strategies, as well as the clinical skill to explain procedures to a "caregiver" in this SLE. This simulation allowed students to develop skills that they would otherwise not all experience in a clinical practicum rotation. Students were able to practice with mannequin dolls and build comfort and confidence without risk of injuring a live infant; they were also able to ask real-time questions as they learned. Students commented on the benefits of hands-on learning with the tools and techniques that are otherwise difficult to learn from didactic classroom instruction. Similar to case example 1 above, first-year graduate students benefited from task trainer mannequins to develop procedural skills while also developing confidence and readiness for clinical practice in pediatric 
feeding. Based on learner feedback, future implementation will also include clinical scenarios to facilitate clinical decision-making as an important next step in student development.

\section{Second-Year Graduate Student Clinical Reasoning Development Examples}

Second-year graduate students at Pacific University continue to learn content related to medical SLP while also starting to gain clinical experiences in non-educational settings. In order to facilitate and foster development of clinical reasoning and critical thinking skills related to coursework in cognition, multiple hands-on lab experiences are provided as learning opportunities (Lemoncello et al., 2015). The next two case examples describe how simulated patient experiences facilitated development of clinical reasoning skills while students were building on medical SLP clinical competencies.

Case 3: Spaced-Retrieval Simulated Patient Training. Spaced Retrieval (SR) is an evidencebased therapy technique that can be used to systematically instruct clients with significant memory and learning challenges to learn new facts, verbal scripts, procedures, and behavioral routines (Hopper et al, 2005; Velikonja et al., 2014). Although the Pacific University graduate program has two courses covering cognitive rehabilitation [i.e., acquired brain injury (ABI) and progressive neurological disorders (progressive)], it was important for the course instructors to collaborate to help students realize that the same procedure (SR) could be used effectively across both populations. Faculty elected to engage students in clinical simulation through simulated patient role-play in order to provide students with the experience of both playing the role of client and clinician.

Preparation. Students were concurrently enrolled in both the ABI and Progressive courses during Fall semester of their second year. Prior to the SLE, students learned about the SR technique in both courses through reading assignments and didactic classroom learning. The Spaced Retrieval (SR) day was a full-day (5-hour) experience designed to provide students with the opportunity to practice this widely-used therapy technique across a variety of cases and clinical scenarios. The first hour included a brief lecture to review the SR technique and clinical video examples illustrating SR for various targets. The second hour introduced the SR screening and treatment procedures and provided for whole-group practice with the technical procedures. Faculty collaborated to develop clinical case scenarios that represented a variety of client profiles (e.g., age, diagnosis, co-occurring challenges) to teach a variety of instructional targets (e.g., use of a walker, use of an external aid planner, recall of the client's room number) using the SR technique (see Table 4). The remaining three hours consisted of patient simulation role-play (SLE described below). 
Table 4

Selected Information Provided to Students for Spaced Retrieval Simulated Patient Day.

\begin{tabular}{|c|c|c|}
\hline & $\begin{array}{l}\text { Client description provided to student } \\
\text { playing the "clinician" role }\end{array}$ & $\begin{array}{l}\text { Client characteristics provided to student } \\
\text { playing the "client" role }\end{array}$ \\
\hline $\begin{array}{l}\text { Case } 1 \\
\text { Severe } \\
\text { TBI }\end{array}$ & $\begin{array}{l}\text { - } 37 \text { yo M s/p severe TBI } 2^{\circ} \text { assault; } \\
\text { coma x3 days; PTA x1 week } \\
\text { - PMH: depression/anxiety (stable } \\
\text { with meds) \& ADHD } \\
\text { - Currently: } 2 \text { weeks post-injury }\end{array}$ & $\begin{array}{l}\text { - Screener: OK first two trials, but } \\
\text { struggle on step } 3 \text { (then pass) } \\
\text { - Distractible (lose focus, make } \\
\text { tangential comments) } \\
\text { - You'll do okay at } 30 \text { second- and 1- } \\
\text { minute delays; Struggle at 2-minute \& } \\
\text { 5-minute delays, especially after } \\
\text { interval distractions initially }\end{array}$ \\
\hline $\begin{array}{l}\text { Case } 2 \text { - } \\
\text { Moderate } \\
\text { TBI }\end{array}$ & $\begin{array}{l}\text { 53yo F s/p moderate TBI } 2^{\circ} \text { motor } \\
\text { vehicle crash } \\
\text { - PMH: high blood pressure \& } \\
\text { diabetes } \\
\text { - Currently: 1-week post-injury }\end{array}$ & $\begin{array}{l}\text { - Screener: OK } \\
\text { - Get confused when information is } \\
\text { presented too quickly or if there's too } \\
\text { much info } \\
\text { - You'll do okay with 1- and 2-minute } \\
\text { delays, but struggle at 5-minute delay } \\
\text { (hesitate, start to just flip through book } \\
\text { randomly) }\end{array}$ \\
\hline $\begin{array}{l}\text { Case } 3- \\
\text { Parkinson } \\
\text { Disease }\end{array}$ & $\begin{array}{l}\text { - } 78 \text { yo F referred to you in SNF for } \\
\text { safety concerns following a fall } \\
\text { - PMH: PD diagnosed } 8 \text { years ago, } \\
\text { low vision due to glaucoma, uses a } \\
\text { cane for mobility } \\
\text { - Currently scored } 23 \text { on the MOCA; } \\
\text { staged as a } 3 \text { on the GDS. }\end{array}$ & $\begin{array}{l}\text { - Screener: OK } \\
\text { - You are very social and chatty, aiming } \\
\text { to please - you seem very "normal" } \\
\text { with a slight hand tremor on the left } \\
\text { and squint a lot } \\
\text { - You'll continue to tell the clinician } \\
\text { you are fine and don't need it but will } \\
\text { struggle following the screening } \\
\text { procedure and start to get frustrated } \\
\text { - During longer breaks, try to initiate } \\
\text { getting up (without cane) to retrieve } \\
\text { something (like getting clinician } \\
\text { coffee) so that they have to remind you } \\
\text { about procedure }\end{array}$ \\
\hline $\begin{array}{l}\text { Case } 4 \text { - } \\
\text { Mild } \\
\text { Dementia }\end{array}$ & $\begin{array}{l}\text { - } 72 \text { yo } \mathrm{M} \text { referred to you in LTC for } \\
\text { issues related to orientation and } \\
\text { wandering } \\
\text { - PMH: adult onset diabetes, } \\
\text { cardiovascular disease, cataracts, } \\
\text { dentures }\end{array}$ & $\begin{array}{l}\text { - Screener: OK first two trials, but } \\
\text { struggle on step } 3 \text { (then pass) } \\
\text { - You seem a bit embarrassed that you } \\
\text { can't remember your room number and } \\
\text { use a lot of face-saving language (e.g., } \\
\text { I'm sorry; this place is just so big) }\end{array}$ \\
\hline
\end{tabular}




\begin{tabular}{|c|c|c|}
\hline & $\begin{array}{l}\text { - No mobility problems } \\
\text { Pt. lives in a dementia community } \\
\text { for the last } 2 \text { months; no family in the } \\
\text { area }\end{array}$ & $\begin{array}{l}\text { - You'll respond to reminiscent } \\
\text { activities during the time between cues } \\
\text { and will want to talk about your } \\
\text { experience in the military }\end{array}$ \\
\hline $\begin{array}{l}\text { Case } 5- \\
\text { Moderate } \\
\text { Dementia }\end{array}$ & $\begin{array}{l}\text { - } 90 \text { yo M referred to you in LTC for } \\
\text { issues related to an increase in } \\
\text { anxiety and aggressive behavior } \\
\text { PMH: high blood pressure, arthritis, } \\
\text { and uses a wheelchair for mobility } \\
\text { - Pt. lives in a dementia community } \\
\text { for the last } 18 \text { months; has family in } \\
\text { the area. }\end{array}$ & $\begin{array}{l}\text { - Screener: struggle first time at steps } 2 \\
\text { and } 3 \text { (but pass) } \\
\text { - You are disoriented and confused to } \\
\text { where you are and who people } \\
\text { are...this is making you agitated } \\
\text { - You'll respond positively to } \\
\text { participating in Montessori type } \\
\text { activities that resemble home tasks } \\
\text { and start to get less anxious }\end{array}$ \\
\hline
\end{tabular}

Equipment. Faculty assembled treatment materials for the SR training (e.g., walkers, external aid planners) and also selected an array of clinical materials that students could select from for each client scenario (e.g., word searches, math worksheets, reading comprehension worksheets, reminiscence images, Montessori activities) in order to fill progressively longer intervals during the SR training with materials appropriate to each client profile.

Learning Objectives. The purpose of this SLE was to provide students the opportunity to engage in clinical scenarios in order to develop deeper understanding of how a technical procedure can be applied to a variety of instructional targets with a variety of client profiles. Specific learning objectives included: (a) demonstrate proficiency in SR procedures (e.g., how to respond when a client provides a correct or incorrect response), (b) adjust SR procedures to adapt to various client profiles (e.g., select an appropriate starting interval), (c) implement SR procedures to teach a variety of instructional targets (facts, procedures), and (d) select client-focused distractor activities to keep the client engaged.

Pre-Briefing. As part of the pre-briefing for this SLE in the morning, faculty instructed students on the purpose of this SLE (including the opportunity for low-stakes practice with patient simulation role-play), logistics for the day, the learning objectives, that faculty would provide onsite supervision and feedback, and that competency assessment would not count toward their course grade.

SLE Procedure. Four faculty participated in this SLE. Following the morning instruction and a lunch break, students spent three hours in the afternoon engaged in patient simulation role-play clinical scenarios and debriefing. Working in pairs, each dyad worked through five different stations for about 30 minutes each. Students in each dyad alternated playing the role of clinician or client. At each station, faculty had prepared brief instructions for each role-play: one short, written scenario for the "clinician" (including demographic information, diagnosis, past medical history, current cognitive-communication profile, setting, and a goal) and one short, written scenario for the "client" (notes about how to perform on the initial SR screening procedure, other co-occurring cognitive-communication challenges to display, and prompts for when and how to struggle with the learning). These written instructions provided a layer of standardization across 
the student experience. The students worked together to establish a realistic and functional goal for each "client," complete the initial SR screening, and to develop a client-focused SR training program. Faculty circled the room to offer instruction, modeling, coaching to the "clients," feedback to the "clinicians," and to answer questions.

Debriefing. After each 30-minute simulation role-play scenario, there was a brief whole group debriefing to discuss faculty observations, student experiences, and insights. Debriefing questions to the whole group included prompts such as: "How did you need to adjust your treatment to match the client's profile? How did this scenario compare to the previous scenario? How did you keep the client engaged during this session?" Additionally, at the end of the day, a whole-group debriefing session was conducted. Each of the four learning objectives was revisited, faculty offered specific feedback related to commonly observed challenges (e.g., providing concise and clear instructions or feedback), students were asked to reflect on their skill development across the five stations, faculty reinforced how SR can be used with a variety of clients to teach a variety of instructional targets in clinical practice, and faculty answered any remaining questions.

Assessment. By the end of this SLE, each learner was able to demonstrate knowledge and skill competency to meet the four learning objectives; faculty worked with students along the way to help develop their clinical skills as needed. During Fall 2017, an IRB-approved survey study was conducted to gather data about student experiences and attitudes about this SLE. An optional anonymous survey was administered through the Learning Management System in conjunction with the ABI course both before and after the SLE. Both surveys asked students to rate their levels of agreement or disagreement on a 5-point Likert-type scale with eight knowledge statements related to SR (see Table 5). Due to the non-normal distribution of this small sample, MannWhitney $U$ tests evaluated for statistically significant change from pre- to post-ranking. Additionally, the post-SLE survey also asked students to rate their levels of agreement or disagreement with eight additional statements about how different components may have contributed to their learning (see Table 6). The post-survey also included one open-ended question to gather any additional comments or feedback about the experience or recommended changes. $94 \%(33 / 35)$ of students completed the pre-lab survey, and $57 \%$ (20/35) of students completed the post-lab survey. 


\section{Table 5}

Changes in Student Knowledge and Confidence Pre- and Post-Lab

\begin{tabular}{|c|c|c|c|}
\hline Statement & Median & $U$ & $p$ \\
\hline I understand what Spaced Retrieval is. & $\begin{array}{l}\text { Pre: } 4.0 \\
\text { Post: } 5.0\end{array}$ & 106.5 & $.000 *$ \\
\hline I understand how to assess candidacy for Spaced Retrieval. & $\begin{array}{l}\text { Pre: } 4.0 \\
\text { Post: } 5.0\end{array}$ & 50.0 & $.000^{*}$ \\
\hline I understand when I should use Spaced Retrieval. & $\begin{array}{l}\text { Pre: } 4.0 \\
\text { Post: } 4.0\end{array}$ & 179.0 & $.002 *$ \\
\hline $\begin{array}{l}\text { I understand how to implement Spaced Retrieval for adults with } \\
\text { acquired brain injury. }\end{array}$ & $\begin{array}{l}\text { Pre: } 4.0 \\
\text { Post: } 5.0\end{array}$ & 133.5 & $.000 *$ \\
\hline $\begin{array}{l}\text { I understand how to implement Spaced Retrieval for adults with } \\
\text { progressive cognitive impairments. }\end{array}$ & $\begin{array}{l}\text { Pre: } 3.0 \\
\text { Post: } 5.0\end{array}$ & 84.0 & $.000 *$ \\
\hline $\begin{array}{l}\text { I understand how Spaced Retrieval can be applied to a variety of } \\
\text { therapy goals/targets. }\end{array}$ & $\begin{array}{l}\text { Pre: } 4.0 \\
\text { Post: } 5.0\end{array}$ & 146.5 & $.000 *$ \\
\hline $\begin{array}{l}\text { I understand how to flexibly apply Spaced Retrieval to a variety of } \\
\text { client severity levels. }\end{array}$ & $\begin{array}{l}\text { Pre: } 3.0 \\
\text { Post: } 4.0\end{array}$ & 94.5 & $.000 *$ \\
\hline I feel confident that I could implement Spaced Retrieval. & $\begin{array}{l}\text { Pre: } 3.0 \\
\text { Post: } 4.0\end{array}$ & 114.0 & $.000 *$ \\
\hline
\end{tabular}

*Denotes statistical significance at $p<.05$.

Note. Rating scale ranged from $1=$ Strongly Disagree to $5=$ Strongly Agree. 
Table 6

Student Impressions about the SLE Components that Contributed to Learning

Statement $\quad$ M

(SD)

The morning lecture contributed to my learning.

4.60

$(0.60)$

Playing the role of the clinician contributed to my learning.

$(0.60)$

The hands-on experience at each station contributed to my learning.

The variety of $\mathrm{ABI}$ and Progressive cases contributed to my learning.

The readings contributed to my learning.

Selecting individualized materials for filling the intervals contributed to my 4.30 learning.

Repeated practice across stations contributed to my learning.

Playing the role of the client contributed to my learning.

Note. Rating scale ranged from $1=$ Strongly Disagree to $5=$ Strongly Agree.

Responses from nine students to the open-ended question offered additional feedback about this experience, reflecting both positive feedback and ideas for improvement:

- "This experience really solidified and increased my learning and awareness for spaced retrieval! Very well spent class time working on these cases!"

- "In particular, seeing both types of patients side-by-side provided a clear picture of the similarities and differences between patients with ABI or dementia."

- "I liked that my professors circulated and helped students by modeling and offering feedback. I liked that there was so many materials to choose from to see what your client responded best to during intervals - reinforced my learning of reminiscence and Montessori therapy techniques also. I felt like I had adequate time to benefit and learn from each station."

- "Great learning experience! It felt slightly long - one less station may have made it slightly less exhausting! It was tiring being both client and clinician, but definitely a worth-while experience." 
- "I am a person who learns best from watching and observing, not jumping into things I don't understand yet. This was a good idea, and it was okay, just not really the best for my learning style."

- "I'm not sure how to generalize this to real patients yet. It's really hard to see how this maps onto real people when we use students as patients. Things go differently when the person sitting across from you actually has real deficits."

Reflection. This experience was the first-time faculty collaborated across these two related courses to help direct student learning to the application of the SR procedure applied to different client diagnoses and profiles. This collaboration allowed faculty to interact with students while tying the clinical simulation experience back to their classroom discussions. Students reported greater confidence in their understanding of SR as a result of this SLE; integrating a clinical application simulation experience in addition to didactic classroom learning enhanced student learning. Students reported greater benefits from playing the role of the clinician compared to the role of the client. Feedback to the open-ended questions also provided insights from two students about how this type of role-play simulation may not be the best fit for all learning styles. Even though two students mentioned how fewer scenarios may have accomplished the same goal, faculty did observe how the first role play scenario required more time than anticipated (nearly 45 minutes). While the faculty was initially worried, they were pleased to see student improvement with procedural fluency such that by the third, fourth, and fifth scenarios, students displayed efficient task completion and confident clinical reasoning to complete the scenario in under 20 minutes. Future research could investigate how many different opportunities and client profiles may be sufficient to develop such clinical problem-solving skills. Having students play the role of both client and clinician offered the opportunity to gain additional insights into how co-occurring challenges with attention, language, awareness, or mobility could impact clinical soft-skills required to maintain client engagement, although additional training for procedural fidelity in patient simulation is likely necessary. While it is not possible to conduct this type of simulated experience for every clinical technique, program, or approach, this SLE is one approach to help students solidify their learning and develop clinical reasoning skills for a widely-used, evidencebased intervention.

Case 4: Cognition \& Feeding Simulated Patient Training. Faculty again collaborated on a fullday SLE focused on the honing clinical skills for supporting feeding and the impact of cognitive impairments on feeding among older adults. The "Cognition \& Feeding" day was another full-day experience designed to provide students the opportunity to integrate their previously acquired knowledge of dysphagia, feeding, and swallowing (taught in the second semester) with their emerging knowledge of cognitive rehabilitation, communication in dementia, and behavior management for adults with cognitive challenges (taught in the fourth semester). Given the high prevalence of feeding and swallowing disorders on a medical SLP's caseload (ASHA, 2019), and the importance of maximizing clients' nutrition and hydration status through effective behavioral management (Coyne \& Hoskins, 1997), this second immersive clinical learning experience was created. This simulated patient experience provided students the opportunity to integrate their knowledge across courses in a safe learning environment.

Preparation. Two faculty participated in this SLE. As with the SR day, students were concurrently enrolled in both the ABI and Progressive courses during Fall semester of their second year. The 
Cognition \& Feeding Day was a full-day (5-hour) experience designed to provide students with the opportunity to develop clinical problem-solving and adjust their feeding interventions across a variety of cases and clinical scenarios. The first hour included a brief lecture to review the feeding and swallowing, and the potential impacts of cognitive impairments on feeding were illustrated through 4 video examples. In the second hour, students worked in small groups (5 students each) to independently research and critically think about how a specific symptom (e.g., attention impairments, sensory impairments, upper extremity limitation and utensil management, environmental factors) might impact feeding. Students had 30 minutes to investigate their symptom in a web-based search and develop compensatory recommendations. Then, each group summarized and shared their findings with the whole class. Faculty offered additional summaries and insights as each group shared their recommendations.

Prior to the SLE, faculty also collaborated to develop seven clinical patient profiles that represented a variety of clients (e.g., age, diagnosis, co-occurring challenges) that could leave patients vulnerable to challenges with feeding and nutritional intake. For this SLE, faculty simulated patients with ABI or progressive illness in order to provide students with "real-life" clinical portrayals. Faculty portraying the simulated patients had clinical experience working with these populations and created fidelity checklists of behavioral profiles to portray relevant swallowing, speech, cognitive-communication, mobility, and other relevant symptoms (e.g., the simulated patient with Parkinson Disease presented with oropharyngeal dysphagia characterized by decreased rotary chew pattern, decreased labial seal, slowed anterior-posterior transit time with tongue pumping, occasional coughing after the swallow, and also masked facies, distractibility, postural rigidity, hypokinetic dysarthria, and resting hand tremor). The remaining three hours consisted of patient simulation with standardized patients (SLE described below).

Equipment. Faculty assembled materials for the SLE, including a full assortment of hot and cold foods (e.g., spaghetti, garlic bread, corn, green beans, pudding, coffee, water), feeding utensils (e.g., forks, knives, spoons, adaptive utensil handles, rocker knife), and food presentation materials (e.g., trays, bowls, divided plates, cups, weighted mugs, straws). The array of choices allowed students to make decisions about the best mode of presentation for specific patient profiles.

Learning Objectives. The purpose of this SLE was to provide students the opportunity to integrate their knowledge across courses to learn supportive feeding techniques to optimize nutritional intake for a range of patients with varying cognitive-communication impairments. Specific learning objectives included: (a) adapt feeding interventions to support optimal intake for adults with various sensory, motor, cognitive, and behavioral profiles, and (b) adjust interventions to respond to patient behaviors while focusing on maximal, safe nutritional intake for each patient.

Pre-Briefing. As with the SR SLE, faculty began the pre-briefing with a description of the purpose of this SLE, logistics for the day, the learning objectives, and that competency assessment would not count toward their course grade.

SLE Procedure. Following the morning instruction and a lunch break, students spent three hours in the afternoon engaged in an SLE with simulated patients portrayed by trained faculty. One faculty member would portray the simulated patient while another faculty member would facilitate each scenario. Students worked in their same small groups (5 students each). Each group was 
provided a brief written clinical scenario describing an adult client with a cognitivecommunication disorder who also was struggling with feeding (with or without dysphagia). Each group had to select and prepare a meal tray to present to the patient. One member of the group would then present the tray to the "patient," and work with the client for 15-20 minutes to facilitate safe and efficient intake. Students within each group could offer suggestions to the "clinician," and could swap out at any time. The faculty facilitator also offered real-time feedback, observations, and support for clinical decision-making (e.g., "I wonder if they might benefit from a different [utensil, presentation, environment, food choice]"). Faculty took care to not point out individual student struggles in front of the whole group but focused on scaffolding for clinical decision-making. The simulated patient for each scenario demonstrated individualized behaviors, such as reduced initiation, distractibility, limited upper extremity use, left neglect, verbose and tangential language, or confusion. All 35 students remained engaged during each scenario through this fishbowl activity (Pearson et al., 2018); while one group was engaged in the center of the room, other groups were observing, offering insights and suggestions, and reflecting on clinical problem-solving.

Debriefing. After each 30-minute simulation, there was a brief, whole group debriefing to discuss faculty observations, student experiences, and insights. Debriefing questions to the whole group included prompts such as: "What do you think was the feeding objective for this client? What behaviors did you observe that interfered with feeding and eating? Which techniques or adaptations did or did not help this patient? Why?" Faculty initially observed that students observing from outside the "fishbowl" generated greater clinical insights and more flexible alternatives compared to students within each group, likely due to added "performance" pressure. However, with repeated practice across the seven scenarios, faculty observed students becoming more willing to engage and offer increasingly flexible solutions in the moment as they became more experienced. Additionally, at the end of the day, a whole-group debriefing session was conducted. In this session, both of the learning objectives were revisited, faculty offered specific feedback related to commonly-observed challenges (e.g., flexibly approaching each individual patient by observing the challenge, trying a technique, and analyzing the patient's response). Additionally, students were asked to reflect on their skill development across the seven scenario's stations, faculty reinforced the impact of cognitive, sensory, environmental, and other factors in addition to dysphagia that can impact eating and nutritional intake, and faculty answered any remaining questions.

Assessment. By the end of this SLE, each small group of learners was able to demonstrate knowledge and skill competency to meet the two learning objectives, and the faculty facilitator worked with students during each scenario to help develop their clinical skills. During Fall 2017, an IRB-approved survey study was conducted to gather data about student experiences and attitudes about this SLE. An optional anonymous survey was administered through the Learning Management System in conjunction with the ABI course both before and after the SLE. Both surveys asked students to rate their levels of agreement or disagreement on a 5-point Likert-type scale with four clinical skill statements about cognition and feeding (see Table 7). Due to the nonnormal distribution of this small sample, Mann-Whitney $U$ tests evaluated for statistically significant change from pre- to post-ranking. Additionally, the post-SLE survey also asked students to rate their levels of agreement or disagreement with eight additional statements about how different components may have contributed to their learning (see Table 8). The post-survey 
also included one open-ended question to gather any additional comments or feedback about the experience or recommended changes. 91\% (32/35) of students completed the pre-lab survey, and $51 \%(18 / 35)$ of students completed the post-lab survey.

\section{Table 7}

Mann-Whitney U test Results Evaluating Student Pre- and Post-Lab Self-Reported Competence and Confidence.

\begin{tabular}{lllc}
\hline Assessment Question & Median & $U$ & $p$ \\
\hline $\begin{array}{l}\text { I understand how cognition can affect feeding/eating. } \\
\text { Pre: } 2.0 \\
\text { Post: } 2.0\end{array}$ & 212.0 & .055 \\
\hline $\begin{array}{l}\text { I understand why feeding/eating can be problematic in long-term } \\
\text { care. }\end{array}$ & $\begin{array}{l}\text { Pre: } 2.0 \\
\text { Post: } 2.0\end{array}$ & 238.0 & .198 \\
\hline $\begin{array}{l}\text { I understand how to flexibly apply management techniques to a } \\
\text { variety of client profiles. }\end{array}$ & $\begin{array}{l}\text { Pre: } 1.0 \\
\text { Post: } 2.0\end{array}$ & 139.5 & $.001^{*}$ \\
\hline $\begin{array}{l}\text { I feel confident that I could support feeding/eating for a client with } \\
\text { cognitive challenges. }\end{array}$ & $\begin{array}{l}\text { Pre: } 1.0 \\
\text { Post: } 3.0\end{array}$ & 156.5 & $.003 *$ \\
\hline
\end{tabular}

*Denotes statistical significance at $p<.05$.

Note. Rating scale ranged from $1=$ Strongly Disagree to $5=$ Strongly Agree.

Students showed an increased understanding of how to apply techniques and an increase in confidence that they could support clients with cognitive-communication disorders on feeding goals. Students however did not indicate an increase in their understanding of the problem or barriers to the work. This may have been due to previous learning and discussions within their course work. 


\section{Table 8}

\section{Student Impressions about the SLE Components that Contributed to Learning}

Statement $\quad$ M

(SD)

Witnessing the variety of ABI and Progressive cases contributed to my learning. 4.44

This lab experience was a good use of class time.

The readings contributed to my learning.

The morning group research on a special topic contributed to my learning.

The morning group summary presentations contributed to my learning.

Presenting and managing the meal contributed to my learning.

Preparing a meal for our group's case contributed to my learning.

I had ample opportunity to practice and learn during the meals.

Note. Rating scale ranged from $1=$ Strongly Disagree to $5=$ Strongly Agree.

Furthermore, responses from nine students to the open-ended question offered additional feedback about this experience, reflecting both positive feedback and ideas for improvement:

- "I wouldn't change a thing. It was a great learning experience!"

- "It was good to have the other faculty 'drop in' to help a little bit when we were going in the wrong direction."

- "I would have loved more modeling before the groups officially began to provide more opportunity to replicate and refine as opposed to or in addition to just trying it out and having help jump in to coach/model when issues arose."

- "I could have gone for a little more lecture and/or specific instructions. I love being thrown into the deep end, it's how we learn, but I also have no idea how to position a spoon in someone's hand, and I had trouble intuiting it."

Reflection. This collaborative SLE again allowed faculty to focus student learning on techniques that could be used to support feeding among adults with cognitive-communication impairments despite underlying diagnoses of acquired or progressive disorders. Faculty felt confident in their portrayals of the standardized patients but would have benefitted from greater pre-briefing together 
to understand how they expected students to respond and adapt, as well as better guide students to expected solutions. Since this SLE was conducted at the end of the fourth semester, when students had already completed didactic coursework, the nature of this simulation was designed to focus more on on-line clinical problem-solving and integration. As a result of this Cognition \& Feeding SLE with patient simulations, students reported greater knowledge of and confidence with how to flexibly apply management techniques to a variety of profiles. Students reported that the variety of patient profiles and focus on specific aspects of feeding supports helped facilitate their learning, with less agreement about the benefits of the fishbowl format (i.e., lower overall ratings for how preparing, presenting and managing the meal contributed to individual learning). Students rated the opportunity to practice and learn during this SLE much lower, likely because each group was only "active" for one of the seven scenarios. Feedback to the open-ended question also provided insights from three students who would have preferred more initial modeling and specific instruction (e.g., how to position utensils) and one student who commented on the challenge of 'performing' in the fishbowl. Although the fishbowl format may have been difficult for some students, faculty did also observe that the "outside" students were equally engaged through the simulations and offered insights to assist the "inside" students in a supportive manner. Future research could attempt to decouple this patient simulation from the fishbowl format using small group work or rotating through stations as in case examples 2 and 3 above. Nonetheless, students reported this was an overall worthwhile experience that allowed them to better apply clinical knowledge for a population they are likely to encounter in medical settings.

\section{Discussion}

SLEs provide an opportunity for each learner to develop technical, critical thinking, and clinical problem-solving skills in a standardized fashion. SLEs should provide multiple, authentic learning opportunities in a safe environment with real-time feedback and "expert" clinician modeling with focused learning objectives aimed at the student's developmental readiness for clinical skills (Dudding et al., 2019). Despite growing interest in SLE, there is a need for faculty training and resource investment to demonstrate the effectiveness of SLE while ensuring clinical competency development (Dudding \& Nottingham, 2018). In this manuscript, the authors shared how faculty collaboration across four different SLEs using task trainers, mannequins, and standardized patients integrated into the medical SLP curriculum at one University resulted in improved skill development, clinical competency, and confidence.

SLEs should align with a student's developmental readiness. In the first two case examples presented in this paper, task trainers were used to foster technical skills among first-year graduate students. Assessment results highlighted that specific training with repeated practice opportunities allowed students to improve skill fluency while also building confidence. Brown (2017) also described how task-trainer mannequin practice fostered technical skills among graduate students. Interestingly, feedback from students in both of these case examples demonstrated that students were ready for a next level of clinical experience; students requested to begin to pass the FEES endoscope on human participants after the mannequin practice, and students requested more clinical scenarios for pediatric feeding problem-solving after the task trainer practice. In the second two case examples, standardized patient simulations were employed to foster clinical problemsolving and adaptability. Assessment of these two SLEs demonstrated that second-year graduate students with more experience were able to engage in this higher-level problem-solving but also 
still requested additional skill-training for tasks they had not yet fully developed (e.g., utensil management on the Cognition \& Feeding Day) to help build their competence and confidence. There is a need to balance building confidence with technical skills and introducing clinical decision-making in a supportive fashion as students learn both procedural and clinical skills.

The use of simulation can aid in the development of critical thinking for the implementation of evidence-based practice when carried out in intentional ways with targeted objectives (Hill et al., 2017; Jansen, 2015). In addition to skill learning, simulation has also shown that it can increase communication skills. A study by Quail and colleagues (2016) used a Virtual Learning Environment to examine the use of standardized patients, virtual patients, and geriatric volunteers with the goal of exploring growth in student communication skills. The researchers reported that students' self-reflection post-simulation defined 'higher communication knowledge, skills, and confidence after completing a conversational interaction with a communication partner" (Quail et al, 2016, p. 8). The pediatric feeding simulation focused on similar patient communication skills and resulted in students reporting increased confidence in clinical communication and skill.

In addition, an SLE should provide a safe learning environment. Pre-briefing can help create safe learning environments. Best practices for pre-briefing include providing learners with information about the rationale for the SLE, equipment used in the simulation, a description of the scenario, the roles students would play, and a discussion of expectations (Dudding et al., 2019). However, the nature of the SLE activity cannot be one-size-fits-all. Some students reported that it was difficult to "jump in" to a clinical scenario (e.g., Cognition \& Feeding fishbowl activity), and that at times they were focused more on not making mistakes in front of their peers rather than developing clinical skills. Fishbowl-type activities may increase anxiety for some students, whereas working in dyads or small groups without needing to "perform" in front of peers seemed to foster a safer learning environment among students at this university. It seems important to strike a balance between scaffolded learning and support to first develop the "technical" skills. Then offering the opportunity to engage in clinical problem-solving, decision-making, and "jumping in" to various simulated scenarios to scaffold and support learning.

Simulations should be realistic to provide authentic opportunities for learning. Although literature on who should play the role of a client in simulations is scarce, students in these reported SLEs preferred when faculty were the trained simulated patients. Second-year graduate students, even with emerging experience working with adult clients, had likely not yet witnessed a full array of client profiles or developed adequate clinical expertise to engage in nuanced role-play scenarios. Even with written instructions for when to provide accurate or inaccurate responses and cooccurring behaviors, students would also likely benefit from additional training to learn to adequately role-play a standardized patient. When possible, trained actors, faculty, or skilled clinicians should portray the role of patients in a standardized simulation to support students in perceiving the simulation as relevant and realistic (Zraick, 2012).

Jansen (2015) suggested that students need to be given the opportunity to apply their didactic knowledge in a model that supports both reflective practice and experiential learning. Through the recurrent implementation in SLEs across the curriculum, it became apparent that students needed repeated opportunities for practice. Student feedback indicated that the SR day experience with 5 repeated opportunities felt too long, while the Feeding day did not provide enough direct practice. 
Careful design and experimentation with the optimal number of trials and variety of cases must be determined for each SLE that is undertaken. For these reported SLEs, the optimal number of practice opportunities reported by students appears to be three to four.

One should also consider assessment of student learning when developing SLEs. At Pacific University, faculty across the medical SLP curriculum have designed several simulation labs for students to develop clinical skills that are not graded. Offering these non-graded opportunities to develop clinical skills would appear to reduce anxiety about performance and allow learners to focus on skill development. Offering formative feedback from experienced faculty through repeated practice opportunities allows students to learn and develop skills and confidence before a summative assessment. Any student who does not demonstrate clinical competency during the SLE is offered remediation until they can demonstrate the skill. Simulations also provide a standardized way to continue to support learning during remediation. With a focus on developing entry-level clinical skills for important practice areas, SLEs offer a valuable tool to help prepare students for future clinical practice.

There are ample opportunities for future research and assessment of SLEs. Some possible questions for exploration include: how many practice opportunities are required for students to hone skills and confidence, how many clinical scenarios are required for students to demonstrate entry-level clinical decision-making, who should play the role of standardized patients, what type of training is required for students to portray standardized patients, which type of active learning activities best foster clinical skill development (e.g., fishbowl vs. paired simulations), how can faculty efficiently offer summative assessment for large numbers of students in academic courses, and how can other simulation technologies (e.g., computer-based simulation or immersive virtual reality) support student learning in the medical SLP curriculum?

The primary limitation of this reflection manuscript is the potential limited generalizability. The examples, results, and discussion focused on the experiences of a collaborative group of faculty at one university, focused on one aspect of the curriculum (medical SLP). Faculty at other programs who are able to effectively collaborate across academic and clinical education, have access to tools to support simulations (grant funding should be explored), are interested in investing time into simulations to support student learning and skill development, and have administrative support for developing new curriculum ideas would be well-poised to explore similar investigations.

\section{Conclusion}

Due to the dwindling opportunities for traditional clinical placements in medical SLP, simulations and SLEs with task trainers, mannequins, and standardized patients offer unique opportunities for clinical training among SLP graduate programs. The purpose of this paper is to describe four specific SLEs employed across the medical SLP curriculum at Pacific University. Each of these four cases was designed to offer unique learning experiences for student to learn foundational skills not easily achieved without simulation practices. In order to implement a comprehensive simulation program, graduate programs must begin with intentional design and interested trained faculty ready to facilitate such learning opportunities. Simulation procedures including prebriefing and debriefing must also allow students to have repeated practice in a safe learning 
environment with realistic simulations. SLEs can foster student skill development, boost student confidence, and prepare students to effectively enter clinical practice prior to patient contact. Varied opportunities embedded through the curriculum support student development for learning medical SLP clinical skills.

\section{Acknowledgements}

Equipment for the FEES training simulation (portable endoscopy system and mannequin) was funded by a foundation grant from the HEDCO Foundation to Dr. Lemoncello and Professor Frost.

\section{Disclosures}

\section{Amanda Stead, Ph.D., CCC-SLP}

- Financial - Is an employee of Pacific University and receives a salary as part of the position and is currently on a 3-year funded endowed professorship studying the implementation of simulation practices within the program

- Non-Financial - Is a reviewer for TLCSD

Rik Lemoncello, Ph.D., CCC-SLP

- Financial - Is an employee of Pacific University and receives a salary as part of the position; Received a grant from the HEDCO Foundation for FEES equipment

- Non-Financial - Is a reviewer for TLCSD

Caitlin Fitzgerald, M.S., CCC-SLP

- Financial - Is an employee of Pacific University and receives a salary as part of the position

- Non-Financial - None to Disclose

Melissa Fryer, M.A., CCC-SLP

- Financial - Is an employee of Pacific University and receives a salary as part of the position; Received a grant from the HEDCO Foundation for FEES equipment and investigation

- Non-Financial - None to Disclose

Marcia Frost, M.S., CCC-SLP

- Financial - Is an employee of Pacific University and receives a salary as part of the position

- Non-Financial - None to Disclose

Rachel Palmer, B.S.

- Financial - Is a graduate student employee of Pacific University working under Dr. Stead and receives a tuition stipend and salary as part of the position

- Non-Financial - None to Disclose

\section{References}

American Speech-Language-Hearing Association (ASHA). (2002). Knowledge and skills for speech-language pathologists performing endoscopic assessment of swallowing functions [Knowledge and Skills]. www.asha.org/policy 
American Speech-Language-Hearing Association. (2007). How ASHA and others are addressing the greatest challenges facing clinical educators in audiology and speech-language pathology today. http://www.asha.org/Articles/Challenges- Facing-Clinical-Educators/

American Speech-Language-Hearing Association. (2019). SLP Healthcare Survey: Caseload Characteristics. https://www.asha.org/uploadedFiles/2019-SLP-HC-Survey-Caseload.pdf

Bax, L., McFarlane, M., Green, E., \& Miles, A. (2014). Speech-language pathologist-led fiberoptic endoscopic evaluation of swallowing: functional outcomes for patients after stroke. Journal of stroke and cerebrovascular diseases: the official journal of National Stroke Association, 23(3),e195-e200. https://doi.org/10.1016/j.jstrokecerebrovasdis.2013.09.031

Brown, D. K. (2017). Simulation before clinical practice: The educational advantages. Audiology Today, 29(5), 16-24.

Benadom, E. M., \& Potter, N. L. (2011). The use of simulation in training graduate students to perform transnasal endoscopy. Dysphagia, 26(4), 352-360. https://doi.org/10.1007/s00455-010-9316-y

Cook, D. A., Hatala, R., Brydges, R., Zendejas, B., Szostek, J. H., Wang, A. T., Erwin, P. J., \& Hamstra, S. J. (2011). Technology-enhanced simulation for health professions education: A systematic review and meta-analysis. Journal of the American Medical Association, 306(9), 978-988. https://doi.org/10.1001/jama.2011.1234

Council on Academic Accreditation. (2017). Standards for accreditation. https://caa.asha.org/reporting/standards/

Council for Clinical Certification in Audiology and Speech-Language Pathology of the American Speech-Language-Hearing Association. (2014). Standards for the certificate of clinical competence in speech-language pathology. http://www.asha.org/Certification/2014Speech-Language-Pathology-Certification- Standards/

Coyne, M. L., \& Hoskins, L. (1997). Improving eating behaviors in dementia using behavioral strategies. Clinical Nursing Research, 6(3), 275-290. https://doi.org/10.1177/105477389700600307

Dudding, C. D., Brown, D. K., Estis, J. M., Szymanski, C., Zraick, R., \& Mormer, E. (2019). Best Practices in Healthcare Simulations in Communication Sciences and Disorders Guide. Counsel of Academic Programs in Communication Science and Disorders. https://members.capcsd.org/news/Details/capcsd-ebook-best-practices-in-healthcaresimulations-in-communication-sciences-and-disorders-guide-8147

Dudding, C. C., \& Nottingham, E. E. (2018). A national survey of simulation use in university programs in communication sciences and disorders. American Journal of SpeechLanguage Pathology, 27(1), 71-81. https://doi.org/10.1044/2017_AJSLP-17-0015

Hill, A. E., Davidson, B. J., \& Theodoros, D. G. (2010). A review of standardized patients in clinical education: Implications for speech-language pathology programs. International Journal of Speech-Language Pathology, 12(3), 259-270. https://doi.org/10.3109/17549500903082445

Hill, A., Ward, E., Dudding, C., \& Penman, A. (2017). Integrating simulation into your training curriculum: insights from implementation experiences. American Speech Language and Hearing Association Annual Convention, Los Angeles, CA, USA, 8-11 November 2017.

Hopper, T., Mahendra, N., Kim, E., Azuma, T., Bayles, K., Cleary, S., \& Tomoeda, C. (2005). Evidence-Based Practice Recommendations for Working with Individuals with Dementia: Spaced-Retrieval Training. Journal of Medical Speech-Language Pathology, 13(4). 
Jansen, L. J. (2015). The Benefits of Simulation-Based Education. Perspectives on Issues in Higher Education, 18(1), 32-42. https://doi.org/10.1044/ihe18.1.32

Lemoncello, R., McDonnell, C., Stead, A. (2015, November). Graduate course "labs" for academic-clinical integration in SLP [Poster presentation]. American Speech-LanguageHearing Association, Denver, CO.

MacBean, N., Theodoros, D., Davidson, B., \& Hill, A. E. (2013). Simulated learning environments in speech-language pathology: An Australian response. International Journal of SpeechLanguage Pathology, 15(3), 345-357. https://doi.org/10.3109/17549507.2013.779024

Pearson, S. C., Eddlemon, T., Kirkwood, M., \& Pate, A. (2018). Are fishbowl activities effective for teaching pharmacotherapy and developing postformal thought in pharmacy students? A pilot study. Experiences in Teaching and Learning, 10, 1070-1075. https://doi.org/10.1016/j.cptl.2018.05.009

Quail, M., Brundage, S. B., Spitalnick, J., Allen, P. J., \& Beilby, J. (2016). Student self-reported communication skills, knowledge and confidence across standardized patient, virtual and traditional clinical learning environments. BMC Medical Education, 16(1), 73. Advance online publication. https://doi.org/10.1186/s12909-016-0577-5

Velikonja, D., Tate, R., Ponsford, J., McIntyre, A., Janzen, S., Bayley, M., \& the INCOG Expert Panel. (2014). INCOG recommendations for management of cognition following traumatic brain injury, part V: Memory. The Journal of Head Trauma Rehabilitation, 29(4), 369386. https://doi.org/10.1097/HTR.0000000000000069

Ward, E. C., Baker, S. C., Wall, L. R., Duggan, B. L. J., Hancock, K. L., Bassett, L. V., \& Hyde, T. J. (2014). Can human mannequin-based simulation provide a feasible and clinically acceptable method for training tracheostomy management skills for speech-language pathologists? American Journal of Speech-Language Pathology, 23(3), 421-436. https://doi.org/10.1044/2014_AJSLP-13-0050

Ward, E. C., Hill, A. E., Nund, R. L., Rumbach, A. F., Walker-Smith, K., Wright, S. E., Kelly, K., \& Dodrill, P. (2015). Developing clinical skills in pediatric dysphagia management using human patient simulation (HPS). International Journal of Speech-Language Pathology, 17(3), 230-240. https://doi.org/10.3109/17549507.2015.1025846

Zraick, R. (2012). Review of the use of standardized patients in speech-language pathology clinical education. Journal of Therapy \& Rehabilitation, 19(2), 112-118. 